\title{
Update on Eluxadoline for the Treatment of Irritable Bowel Syndrome with Diarrhea: Patient Selection and Perspectives
}

This article was published in the following Dove Press journal:

Drug Design, Development and Therapy

\author{
Rebecca Liu' \\ Kyle Staller iD ${ }^{1,2}$ \\ 'Department of Medicine, Massachusetts \\ General Hospital and Harvard Medical \\ School, Boston, MA, USA; ${ }^{2}$ Division of \\ Gastroenterology, Department of \\ Medicine, Massachusetts General \\ Hospital and Harvard Medical School, \\ Boston, MA, USA
}

\begin{abstract}
Irritable bowel syndrome (IBS) is a functional gastrointestinal (GI) disorder characterized by chronic abdominal pain associated with changes in bowel habits. It is the most common GI problem seen by gastroenterologists. IBS is a heterogenous disorder encompassing a spectrum of underlying mechanisms and clinical presentations. The pathophysiology of diarrhea-predominant form of IBS (IBS-D) remains poorly understood, and current available therapeutic options for IBS-D are limited. Eluxadoline is a novel, locally acting mixed $\mu$ - and $\kappa$-opioid receptor agonist and $\delta$-receptor antagonist approved by the Food and Drug Administration (FDA) for treatment of adults with IBS-D. Data from two phase III clinical trials showed that approximately $25-30 \%$ of the eluxadoline-treated patients achieved composite clinical response, defined by a reduction of abdominal pain and improvement in stool consistency. Patients who achieve composite response during the first month of therapy were significantly more likely to demonstrate sustained clinical response. The most common adverse events reported with eluxadoline use were constipation, nausea and abdominal pain. The risk of abuse, dependence, or withdrawal is low. Serious adverse events associated with eluxadoline include sphincter of Oddi spasm (SOS) and pancreatitis particularly in patients without a gallbladder. Development of pancreatitis is likely secondary to SOS, but it remains unclear why pancreatitis occurs so quickly after initial doses. This adverse event profile helps guide proper selection of IBS-D patients for eluxadoline use, with important contraindications including absence of a gallbladder, biliary duct obstruction or sphincter of Oddi dysfunction, alcoholism, history of pancreatitis, or structural diseases of the pancreas. With the recent clinical trials demonstrating its efficacy, eluxadoline provides an additional option to the few existing pharmacologic interventions available for IBS-D. In this review, we discuss the drug development, efficacy and safety of eluxadoline, as well as selection criteria for identifying appropriate candidates for this medication.
\end{abstract}

Keywords: eluxadoline, efficacy of eluxadoline, irritable bowel syndrome, IBS, irritable bowel syndrome with diarrhea, IBS-D, IBS-D

\section{Introduction}

Irritable bowel syndrome (IBS) is a complex functional gastrointestinal (GI) disorder characterized by chronic abdominal pain associated with defecation or changes in stool frequency or form. ${ }^{1}$ Additional accompanying symptoms of IBS often include abdominal bloating, straining, or fecal urgency. IBS is the most common GI problem encountered by gastroenterologists, with a worldwide prevalence of $11.2 \%$ and has a significant impact on patients' well-being. ${ }^{2}$ Patients with IBS report substantial impairment in health-related quality of life characterized
Correspondence: Kyle Staller Massachusetts General Hospital, 165

Cambridge St. 9th floor, Boston, MA

021।4-2896, USA

Tel +I 617 724-6038

$\mathrm{Fax}+1617$ 726-3080

Email kstaller@mgh.harvard.edu 
by fatigue, pain, and decreased functionality, including decreased work productivity. ${ }^{3,4}$

IBS is not a single disease entity but a heterogenous group of disorders encompassing a spectrum of pathophysiological mechanisms and clinical presentations. While traditionally regarded as a functional disorder without definitive structural or biochemical abnormalities, emergent evidence now challenges this concept and suggests that multiple processes including disordered brain-gut interaction, post-infectious changes, low-grade mucosal immune activation, ${ }^{5}$ alterations in the gut microbiome, dysregulation of serotonin signaling and bile salt metabolism, and genetic factors likely contribute to the development and maintenance of IBS. ${ }^{6}$ Based on bowel habit pattern, IBS may be grouped into one of four subtypes: IBS with predominant diarrhea (IBS-D), IBS with predominant constipation (IBS-C), IBS with mixed bowel habits (IBS-M) or IBS unclassified (IBS-U). ${ }^{7}$

Per Rome IV diagnostic criteria, patients with IBS-D have more than $25 \%$ of bowel movements with stool consistency meeting the Bristol Stool Form Scale (BSFS) type 6 or 7 , and less than $25 \%$ of bowel movements with BSFS type 1 or 2 (Figure 1). ${ }^{8}$ Current therapy options for IBS-D are limited. Initial therapies typically involve dietary and lifestyle modifications with antidiarrheals and are oftentimes ineffective. ${ }^{9}$ There are currently three FDA-approved medications for IBS-D, namely alosetron, rifaximin and eluxadoline, in addition to off-label use of neuromodulators such as tricyclic antidepressants. Eluxadoline is a peripherally-acting mixed $\mu$ - and $\kappa$-opioid receptor agonist and $\delta$-receptor antagonist that has demonstrated efficacy in IBS-D patients. This review will discuss drug development, efficacy and safety of eluxadoline, as well as selection criteria for identifying appropriate candidates for this medication.

\section{Existing Pharmacologic Treatments for IBS-D \\ Loperamide}

Loperamide, an over-the-counter antidiarrheal drug approved for use in acute, chronic and traveler's diarrhea, is frequently used by patients with IBS-D for symptomatic treatment. Loperamide acts as a synthetic opioid agonist, slowing gut peristalsis and increasing transit time with minimal CNS effects. Two small RCTs $(n=42)$ performed in 1987 evaluated the effect of loperamide in IBS-M and IBS-D, and data from these studies did not reveal a statistically significant difference between loperamide versus placebo $(\mathrm{RR}=0.44 ; 95 \% \mathrm{CI} 0.14$ to
1.42) (Table 1) ${ }^{10,11}$ Despite the proven efficacy of loperamide as an antidiarrheal agent, there is an overall lack of evidence to support the use of loperamide for symptom improvement in IBS-D. ${ }^{12}$

\section{Antidepressants}

Many centrally acting neuromodulators, such as tricyclic antidepressants (TCAs), selective serotonin reuptake inhibitors (SSRIs), and serotonin-norepinephrine reuptake inhibitors (SNRIs), also have peripheral effects in the GI tract and may regulate bowel functions. The TCAs are a class of antidepressants that exert their therapeutic effect primarily through inhibition of presynaptic reuptake of norepinephrine and serotonin. In the gut, TCAs ameliorate diarrhea by slowing intestinal transit time and are commonly used for treatment of IBS-D. With the high prevalence of psychiatric co-morbidities in IBS patients, the use of TCAs may address the overlapping psychological disorders as well as gastrointestinal symptoms, though the doses used for IBS are generally much lower than the doses used in psychiatric disease. Twelve RCTs examining the efficacy of TCAs in IBS ( $\mathrm{n}=787)$ demonstrated improvement of IBS symptoms with TCA use in comparison with placebo $(\mathrm{RR}=0.65 ; 95 \%$ CI 0.55 to 0.77 ) with an number needed to treat (NNT) of 4 (Table 1). ${ }^{12}$ Furthermore, TCAs are also thought to be the most effective neuromodulator for relief of pain. It remains unclear if TCAs are beneficial broadly to all IBS-D patients or only a specific subset, and the use of TCAs may be limited due to patient acceptance as well as common side effects including fatigue and anticholinergic side effects such as dry mouth.

The use of atypical antidepressants for treatment of IBS remains an area of active investigation. Tianeptine is a selective serotonin reuptake enhancer that has demonstrated similar efficacy as SSRIs and TCAs in treating depression and anxiety but has a milder reported side effect profile compared to TCAs. ${ }^{13}$ Noting the prokinetic effect of SSRIs on the GI tract, tianeptine is theoretically beneficial for patients with IBS-D given its opposite mechanism of action from SSRIs. A randomized, non-inferiority clinical study was conducted to evaluate the effectiveness of tianeptine versus amitriptyline, a TCA. ${ }^{14}$ More than 200 patients were randomized to receive either tianeptine or amitriptyline, each with probiotics, for 4 weeks, and global relief of IBS symptoms at week 4 was assessed. Tianeptine was shown to be non-inferior to amitriptyline in treating IBS-D in terms of effectiveness $(81 \%$ and $66 \%$ of patients reported global relief of IBS symptoms in the tianeptine and amitriptyline group, respectively). Furthermore, 


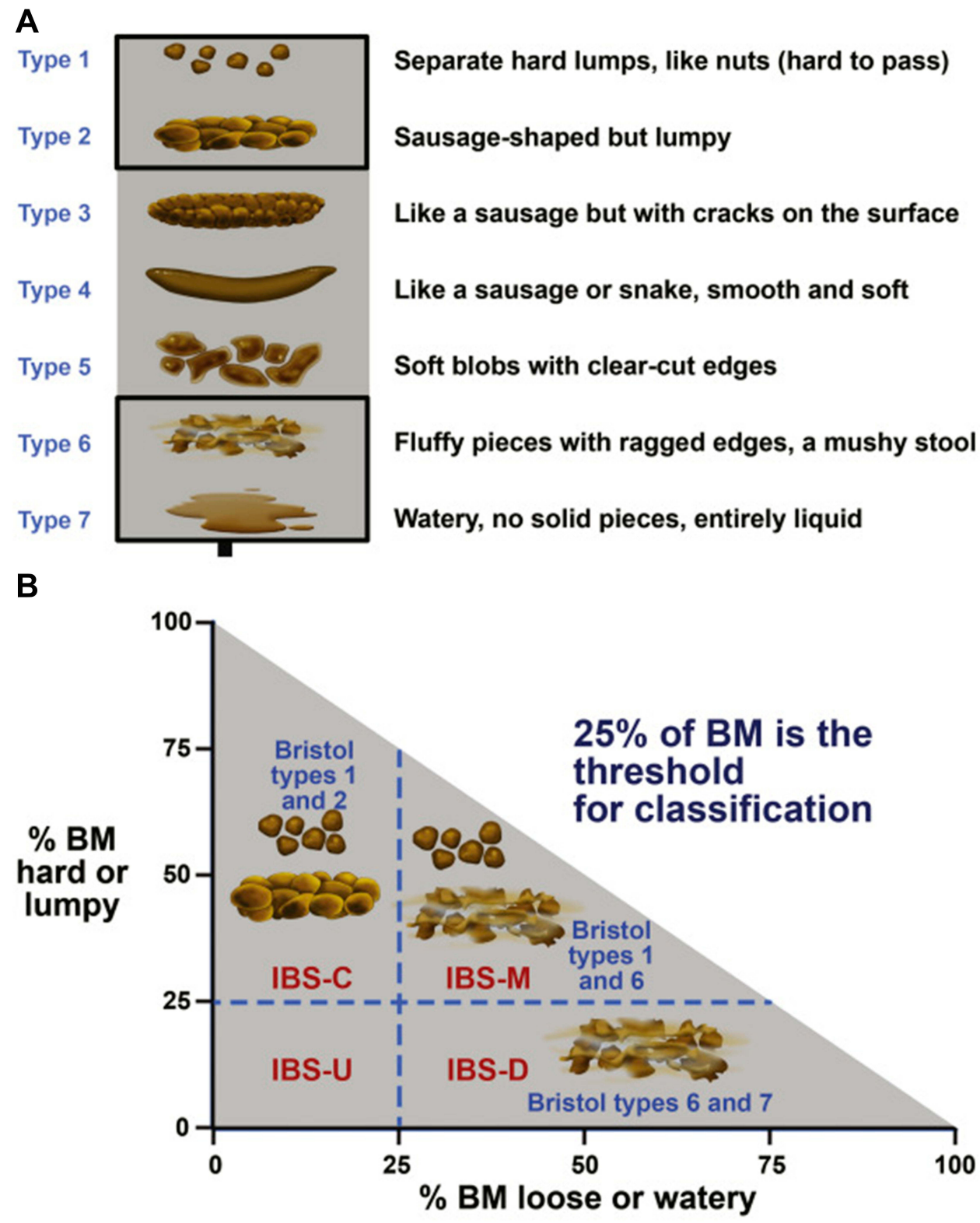

Figure I (A) The Bristol Stool Form Scale (BSFS) is a useful tool to evaluate bowel habit. The BSFS has been shown to be a reliable surrogate marker for colonic transit. (B) IBS subtypes should be established according to stool consistency, using the BSFS. IBS subtyping is more accurate when patients have at least 4 days of abnormal bowel habits per month. Bowel habit subtypes should be based on BSFS for days with abnormal bowel habits. Reprinted from Gastroenterology, I50(6), Lacy BE, Mearin F, Chang L, et al, Bowel disorders, 1393, copyright (2016), with permission from Elsevier. ${ }^{8}$

tianeptine was less likely to cause side effects such as dry mouth and constipation compared to amitriptyline $(\mathrm{p}<0.05)$. Another novel atypical antidepressant, agomelatine, is a naphthalene analog of melatonin and also a serotonin 5-HT3 receptor antagonist. Given the known effect of 5-HT3 antagonism on the motor and sensory functions of the GI tract, it has been hypothesized that agomelatine could be effective for IBS-D. ${ }^{15}$ To date, only one small-scale study examined the role of agomelatine in IBS patients. ${ }^{16}$ Further investigations on the efficacy and tolerability of this drug for treating IBS-D are warranted.

\section{Alosetron}

Alosetron, a selective serotonin 5-HT3 antagonist, was the first FDA-approved medication with a specific indication for IBS-D. It was re-introduced to the US market in 2002 via FDA's risk evaluation and mitigation strategy-since relaxed-after its voluntary withdrawal months after initial approval due to adverse effects including serious complications related to constipation and ischemic colitis. ${ }^{17,18}$ It is approved only for women with severe diarrhea-predominant IBS with chronic symptoms who fail to have an adequate response to conventional 
Table I Summary of Evidence from Randomized Controlled Trials of Existing Pharmacologic Treatments for IBS-D

\begin{tabular}{|l|l|l|l|l|l|l|}
\hline Medication & $\begin{array}{l}\text { Number of } \\
\text { RCTs }\end{array}$ & $\begin{array}{l}\text { Number of } \\
\text { Patients }\end{array}$ & IBS Subtype & $\begin{array}{l}\text { Relative Risk of } \\
\text { Remaining } \\
\text { Symptomatic vs } \\
\text { Placebo (95\% CI) }\end{array}$ & $\begin{array}{l}\text { Number } \\
\text { Needed to } \\
\text { Treat } \mathbf{( 9 5 \% ~ C I )}\end{array}$ & $\begin{array}{l}\text { Recommendation } \\
\text { and Strength of } \\
\text { Evidence }\end{array}$ \\
\hline Loperamide & 2 & 42 & IBS-D or IBS-M & $0.44(0.14-1.42)$ & N/A & Strong, very low \\
Tricyclic antidepressant & 12 & 787 & N/A & $0.65(0.55-0.77)$ & $4(3.5-7)$ & Strong, high \\
Alosetron & 8 & 4987 & IBS-D & $0.79(0.69-0.90)$ & $7.5(5-16)$ & Weak, low \\
Rifaximin & 6 & $244 I$ & IBS-D or IBS-M & $0.86(0.8 I-0.91)$ & $10.5(8-16)$ & Weak, moderate \\
Eluxadoline & 3 & 3235 & IBS-D & $0.91(0.85-0.97)$ & $12.5(8-33)$ & Weak, moderate \\
\hline
\end{tabular}

Note: Adapted with permission from Wolters Kluwer Health, Inc.: Ford AC, Moayyedi P, Chey WD, et al. American College of Gastroenterology Monograph on Management of Irritable Bowel Syndrome. Am J Gastroenterol. 2018;1 I3(Suppl 2):1-18 . ${ }^{12}$

therapies. The definition of severe IBS-D in this context includes diarrhea with one or more of the following: frequent and severe abdominal pain/discomfort, frequent bowel urgency or fecal incontinence, and/or disability or restriction of daily activities due to IBS. ${ }^{19}$ In comparison to placebo, alosetron demonstrates a significantly lower failure rate in relieving IBS pain and discomfort. ${ }^{20}$ Evidence from two studies that enrolled women with more severe IBS-D suggests that alosetron improves global IBS symptoms. ${ }^{21,22}$ A recent systematic review of eight RCTs on alosetron demonstrated a statistically significant benefit of alosetron over placebo ( $R \mathrm{R}=0.79 ; 95 \%$ CI 0.69 to 0.90 ), with an overall NNT of 8 (Table 1). However, the quality of evidence and strength of recommendation was rated as low due to significant heterogeneity between studies. $^{12}$ A 9-year assessment of postmarketing safety of alosetron showed that the incidence of ischemic colitis remained stable ( 1.03 cases/1000 patient-years) whereas the incidence of complications of constipation declined $(0.25$ cases $/ 1000$ patient-years $){ }^{18}$ Despite the low incidence of severe complications, the overall use of alosetron since its reintroduction has been limited. ${ }^{17}$

\section{Rifaximin}

Rifaximin is an oral, non-systemic, antibiotic approved by FDA in 2015 for treatment of IBS-D in adults. It is a shortcourse regimen (14 days) and may be repeated up to two times per year in the setting of recurrent symptoms. ${ }^{23}$ In two double-blind, phase III randomized placebo-controlled trials (TARGET 1 and TARGET 2), a greater proportion of IBS-D patients who received rifaximin experienced relief of global IBS symptoms for at least 2 of the 4 weeks after treatment completion in comparison to patients who received placebo. ${ }^{24}$ Furthermore, rifaximin also reduced IBS-related abdominal bloating. In a subsequent large, open-label phase III study (TARGET 3), 1074 out of 2438 patients (44\%) responded to rifaximin with improvement in abdominal pain and stool consistency. ${ }^{23}$ Approximately $60 \%$ of these patients who initially responded to rifaximin developed recurrent symptoms (median time of relapse was 10 weeks after the first treatment, range from 6 to 24 weeks). ${ }^{9}$ Patients with recurrent symptoms in the TARGET 3 trial were randomized to receive repeated courses of rifaximin (550 mg TID for 14 days for each course) versus placebo, with results demonstrating the efficacy and safety of repeated rifaximin courses. ${ }^{25}$ Repeat treatments also led to sustained symptom relief and prevention of recurrence. While a systemic review of six RCTs shows a statistically significant benefit of rifax$\operatorname{imin}(R R=0.86 ; 95 \%$ CI 0.81 to 0.91$)$, the quality of evidence suggesting its use for IBS-D is only moderate (Table 1). ${ }^{12}$

\section{Eluxadoline}

Eluxadoline was approved by the FDA concurrently with Rifaximin in 2015 for treatment of IBS-D in adult men and women. ${ }^{26,27}$ Mechanistically, eluxadoline is a locally-acting mixed $\mu$-opioid and $\kappa$-opioid agonist $/ \delta$-receptor antagonist. $\mu-, \kappa-$, and $\delta$ - opioid receptors in the gut intricately regulate multiple processes that are fundamental to the proper functioning of the GI tract, including motility, secretion, digestion, and visceral sensation. ${ }^{28}$ While activation of $\mu$-opioid receptors results in a delay of GI transit and attenuation of GI secretion, $\delta$-opioid receptor antagonism seems to promote the propulsive motor activity of the gut. Evidence suggests that $\delta$-receptor antagonism attenuates the strong inhibitory actions of $\mu$-receptor agonists on intestinal contractility and secretion, resulting in more normal bowel function that shows more resemblance to physiologic colonic activity compared to unopposed $\mu$-opioid receptor agonists such as loperamide (Figure 2). ${ }^{29}$ Drug development, efficacy, safety, 


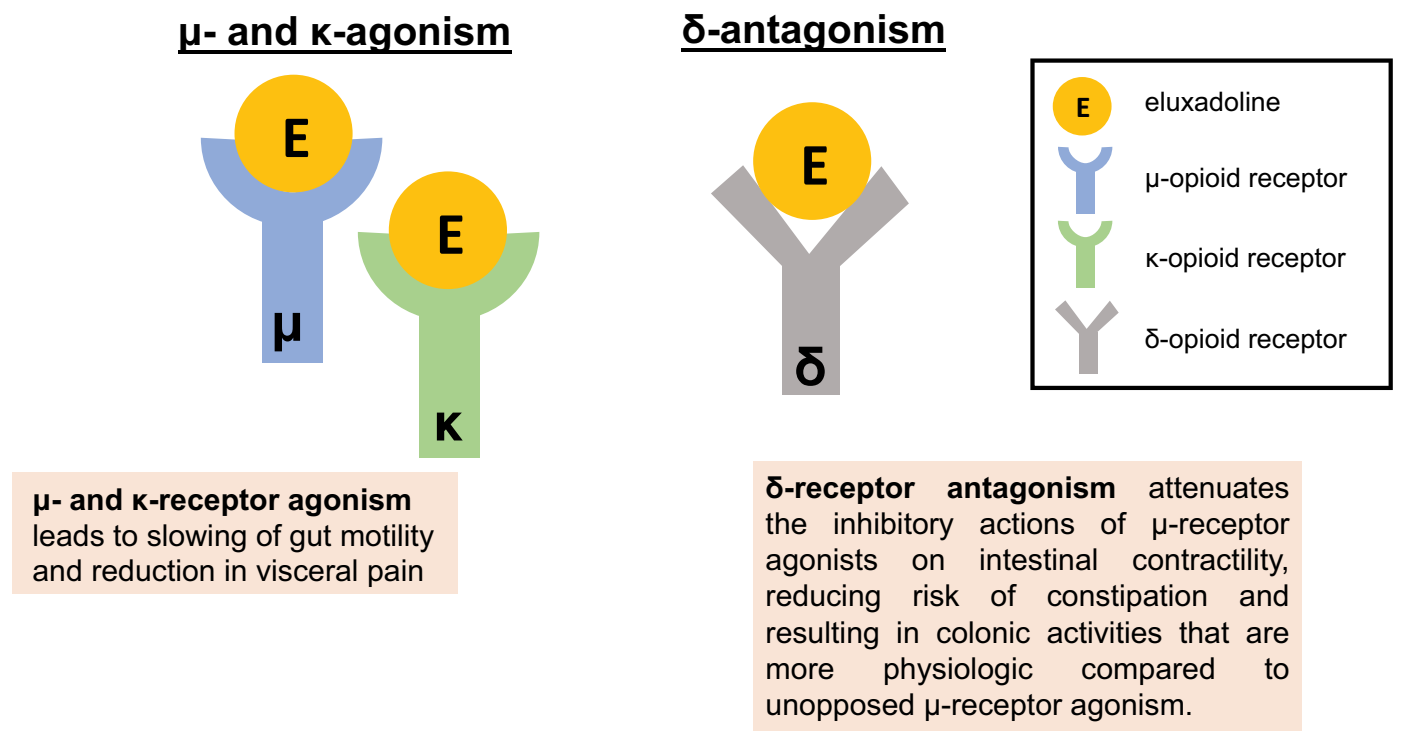

Figure 2 Modulation of GI Motility and Visceral Pain by Eluxadoline. Eluxadoline is a peripherally-acting mixed $\mu$ - and $\kappa$-opioid receptor agonist and $\delta$-opioid receptor antagonist. Activation of $\mu$ - and $\kappa$-opioid receptors results in delay of $\mathrm{Gl}$ transit and reduction in visceral pain, while $\delta$-opioid receptor antagonism promotes the propulsive motor activity of the gut. $\delta$-opioid receptor antagonism appears to attenuate the strong inhibitory actions of $\mu$-opioid receptor agonism on intestinal contractility and secretion, resulting in colonic activities that are more physiologic compared to unopposed $\mu$-opioid receptor agonism.

and perspectives on patient selection for eluxadoline will be discussed in detail in the subsequent sections.

\section{Efficacy of Eluxadoline for IBS-D}

The first double-blind, randomized placebo-controlled phase II trial evaluating the efficacy of eluxadoline for IBS-D was conducted in $2010 .{ }^{30}$ Over 800 patients received placebo or a range of doses of eluxadoline (5-200 mg bid) for 12 weeks. The primary endpoint of this study was clinical response at week 4 assessed by two components: abdominal pain score and stool consistency. Specifically, responders were defined as patients who demonstrated an improvement of mean daily worst abdominal pain (WAP) score (rated on the scale of 1-10) of at least $30 \%$ from baseline and at least 2 absolute points, as well as achievement of stool consistency of BSFS type 3 or 4 for at least two-thirds of daily stool entries at week 4. Twelve percent and $13.8 \%$ of patients receiving $25 \mathrm{mg}$ and $200 \mathrm{mg}$ of eluxadoline, respectively, met the composite clinical response primary endpoint in comparison to $5.7 \%$ of patients receiving placebo. When evaluating by the WAP component only, however, there was no significant difference in pain response rate at week 4 between the placebo and eluxadoline groups. The differences in composite response in the eluxadoline $(25 \mathrm{mg}$ and $200 \mathrm{mg}$ ) versus placebo groups were driven by the greater improvement in stool consistency in the eluxadoline groups. Patients who received the $100 \mathrm{mg}$ or $200 \mathrm{mg}$ doses of eluxadoline also demonstrated improvements in global IBS symptoms, bowel movement frequency, urgency, and quality of life. Subsequently, the FDA released guidance for standardizing clinical outcome measures in IBS trials in $2012,{ }^{31}$ defining responders as patients who demonstrate improvement in WAP by at least $30 \%$ from baseline as well as daily BSFS < type 5 (or reported no bowel movements) in at least $50 \%$ of days of treatment. In this phase II study, patients who were treated with $100 \mathrm{mg}(28 \%)$ or $200 \mathrm{mg}(28.5 \%)$ of eluxadoline were twice as likely to be FDA responders in comparison to patients who received placebo (13.8\%).

The efficacy and safety of eluxadoline for IBS-D were further examined in two randomized, double-blind, multicenter phase III trials conducted between May 2012 and July $2014 .{ }^{32}$ Over 2400 patients were randomized to receive $75 \mathrm{mg}$ or $100 \mathrm{mg}$ of eluxadoline versus placebo twice daily for 26 weeks (IBS-3002) and 52 weeks (IBS-3001). Clinical response was monitored through 26 weeks, while the safety of eluxadoline was assessed through 52 weeks. Responders were defined as patients who showed a daily reduction of WAP by $\geq 30 \%$ from their baseline and simultaneously a BSFS $<5$ or no bowel movement, for $\geq 50 \%$ of the recorded days. From weeks 1 through 12, a significantly greater proportion of patients receiving $75 \mathrm{mg}$ or $100 \mathrm{mg}$ of eluxadoline, as compared to the placebo group, were composite clinical responders. This was true for both the IBS-3001 (23.9\% and $25.1 \%$ for $75 \mathrm{mg}$ and $100 \mathrm{mg}$ eluxadoline, respectively, and $17.1 \%$ with placebo; $\mathrm{p}=0.01$ for $75 \mathrm{mg}$ eluxadoline vs placebo; 
Table 2 Efficacy Data from Phase III Trials Assessing Clinical Response of IBS-D Patients to Eluxadoline*

\begin{tabular}{|c|c|c|c|c|c|c|}
\hline \multirow[t]{2}{*}{ Treatment Groups } & \multicolumn{3}{|c|}{ IBS-300I Trial } & \multicolumn{3}{|c|}{ IBS-3002 Trial } \\
\hline & $\begin{array}{l}\text { Eluxadoline } \\
\text { I00mg BID } \\
(\mathrm{n}=426)\end{array}$ & $\begin{array}{l}\text { Eluxadoline } \\
75 \mathrm{mg} \text { BID } \\
(\mathrm{n}=427)\end{array}$ & $\begin{array}{l}\text { Placebo } \\
(n=427)\end{array}$ & $\begin{array}{l}\text { Eluxadoline } \\
\text { I00mg BID } \\
(\mathrm{n}=382)\end{array}$ & $\begin{array}{l}\text { Eluxadoline } \\
75 \mathrm{mg} \text { BID } \\
(\mathrm{n}=38 \mathrm{I})\end{array}$ & $\begin{array}{l}\text { Placebo } \\
(n=382)\end{array}$ \\
\hline \multicolumn{7}{|l|}{$\begin{array}{l}\text { Composite }{ }^{\mathrm{a}} \text { response over } 12 \\
\text { weeks }\end{array}$} \\
\hline Responder rates & $25 \%$ & $24 \%$ & $17 \%$ & $30 \%$ & $29 \%$ & $16 \%$ \\
\hline Treatment difference & $8 \%^{b}$ & $7 \%^{c}$ & & $13 \%^{d}$ & $13 \%^{d}$ & \\
\hline $95 \% \mathrm{Cl}(\%)$ & $(2.6,13.5)$ & $(1.4,12.2)$ & & $(7.5,19.2)$ & $(6.8,18.5)$ & \\
\hline \multicolumn{7}{|l|}{$\begin{array}{l}\text { Composite response over } 26 \\
\text { weeks }\end{array}$} \\
\hline Responder rates & $29 \%$ & $23 \%$ & $19 \%$ & $33 \%$ & $30 \%$ & $20 \%$ \\
\hline Treatment difference & $10 \%$ & $4 \%$ & & $13 \%$ & $10 \%$ & \\
\hline $95 \% \mathrm{Cl}(\%)$ & $(4.7,16.1)$ & $(-1.0,9.9)$ & & $(6.4,18.8)$ & $(4.2,16.4)$ & \\
\hline \multicolumn{7}{|l|}{$\begin{array}{l}\text { Abdominal pain response } \\
\text { improved by } \geq 30 \% \text { over } 12 \\
\text { weeks }\end{array}$} \\
\hline Responder rates & $43 \%$ & $42 \%$ & $40 \%$ & $51 \%$ & $48 \%$ & $45 \%$ \\
\hline Treatment difference & $4 \%$ & $3 \%$ & & $6 \%$ & $3 \%$ & \\
\hline $95 \% \mathrm{Cl}(\%)$ & $(-3.0,10.2)$ & $(-3.8,9.4)$ & & $(-1.3,12.8)$ & $(-4.3,9.8)$ & \\
\hline \multicolumn{7}{|l|}{ BSS $<5$ Response over 12 weeks } \\
\hline Responder rates & $34 \%$ & $30 \%$ & $22 \%$ & $36 \%$ & $37 \%$ & $21 \%$ \\
\hline Treatment difference & $12 \%$ & $8 \%$ & & $15 \%$ & $16 \%$ & \\
\hline $95 \% \mathrm{Cl}(\%)$ & $(6.3,18.2)$ & $(2.1,13.8)$ & & $(8.4,21.0)$ & $(9.7,22.4)$ & \\
\hline
\end{tabular}

Notes: *Data from Viberzi (eluxadoline) Highlights of Prescribing Information, FDA, $2018,{ }^{27}$ and Lembo et al. ${ }^{22}$ a Composite $=$ Simultaneous improvement of Worst Abdominal Pain by $\geq 30 \%$ and Bristol Stool Form Scale (BSFS) $<5$ on the same day for $\geq 50 \%$ of days over the interval. ${ }^{b} \mathrm{p}<0.0$ I. ${ }^{c} \mathrm{p}<0.05$. ${ }^{\mathrm{d}} \mathrm{p}<0.00 \mathrm{I}$.

$\mathrm{p}=0.004$ for $100 \mathrm{mg}$ eluxadoline vs placebo) and the IBS-3002 (28.9\% and $29.6 \%$ for $75 \mathrm{mg}$ and $100 \mathrm{mg}$ eluxadoline, respectively, and $16.2 \%$ with placebo, $\mathrm{p}<0.001$ ) (Table 2). From weeks 1 through 26 , significantly more patients in the $100 \mathrm{mg}$ eluxadoline group were composite responders compared to patients who received placebo in both the IBS-3001 and IBS-3002 trials $(\mathrm{p}<0.001)$. While the $75 \mathrm{mg}$-dose group demonstrated an overall trend of composite clinical improvement compared to the placebo group, the differences only reached statistical significance in the IBS-3002 trial. Similar to the findings from the phase II trial, ${ }^{30}$ no significant improvement was observed between either dose of eluxadoline and placebo in regard to the mean WAP scores or the proportion of patients who demonstrated reduction of WAP. Both doses of eluxadoline led to an improvement in stool consistency, frequency, urgency, IBS-D global symptoms, adequate relief of IBS symptoms, and the IBS-QOL questionnaire score. To better evaluate the kinetics of treatment benefits with eluxadoline, a post hoc analysis stratified responders vs nonresponders based on composite response (improvement in abdominal pain and stool consistency) and adequate relief response during the first month of treatment. ${ }^{33}$ Over twothirds of first-month responders demonstrated sustained response over 3 months and 6 months. On the other hand, less than $20 \%$ of the first month non-responders became responders during months $1-3$ and months $1-6$. These findings suggest that early response to eluxadoline predicts sustained therapeutic effect in patients with IBS-D.

The over-the-counter antidiarrheal agent loperamide is a commonly used medication of IBS-D. As above, however, the efficacy of loperamide in controlling IBS symptoms is fairly limited. Whether eluxadoline is effective in alleviating symptoms that were inadequately controlled by loperamide is therefore of particular interest. As part of IBS-3001 and IBS 3002 trials, patients were asked to report prior use of loperamide, pattern of use (short-term vs long-term), and whether loperamide had provided adequate control of IBS symptoms. Among patients with inadequate symptoms control with prior loperamide use, a significantly larger proportion of patients treated with $75 \mathrm{mg}$ and $100 \mathrm{mg}$ eluxadoline 
(26.3\% and $27 \%$, respectively), as compared with placebo (12.7\%; $p=0.001$ and $p<0.001$, respectively) were composite responders over 12 weeks of treatment. ${ }^{34}$ Similar findings were reported in another randomized, double-blinded, placebo-controlled phase 4 study enrolling over 300 IBS-D patients who reported inadequate symptom relief with loperamide, suggesting that eluxadoline is effective in alleviating symptoms in a subset of IBS-D patients who failed to achieve symptom control with prior loperamide use. ${ }^{35}$

While the treatment benefits of eluxadoline relative to other pharmacological therapies in IBS-D have not been directly assessed in clinical trials, a recent network metaanalysis compared the efficacy of eluxadoline to three other licensed pharmacological therapies: alosetron, ramosetron (a 5- $\mathrm{HT}_{3}$ antagonist only approved for use in selected Asian countries), and rifaximin. ${ }^{36}$ Analysis of 18 eligible RCTs (seven alosetron, five ramosetron, two rifaximin and four eluxadoline) containing 9844 patients revealed that among the four pharmacologic agents alosetron $1 \mathrm{mg}$ twice daily was the most efficacious agent when evaluated by the FDA-defined composite endpoint (abdominal pain and stool consistency), alleviation of global IBS symptoms, and improvement of stool consistency. Ramosetron $2.5 \mu \mathrm{g}$ daily was most effective for improving abdominal pain, and rifaximin $550 \mathrm{mg}$ TID was ranked first for safety. Overall, the performance of eluxadoline assessed based on the above endpoints was considered modest.

\section{Safety of Eluxadoline in Patients with IBS-D}

In phase 3 clinical trials, the most common adverse events associated with eluxadoline were constipation ( $8 \%$ ), nausea (7.7\%), and abdominal pain $(6.5 \%))^{32}$ The rate of medication discontinuation due to these side effects was low. Pooled safety data from phase 2 and phase 3 clinical trials of eluxadoline identified 10 cases of sphincter of Oddi spasm (SOS) $(10 / 1839 ; 0.5 \%)$ in eluxadoline-treated patients. ${ }^{37}$ All 10 SOS events occurred in patients without a gallbladder. Of these 10 patients, eight had abdominal pain and elevated aminotransferases; one patient had pancreatitis; one patient presented with abdominal pain with mild lipase elevation but did not fulfill the Atlanta criteria for diagnosis of pancreatitis. Eight out of 10 SOS patients took a higher dose of eluxadoline at $100 \mathrm{mg}$. In addition to the aforementioned SOS case, five other events were adjudicated as pancreatitis based on the Atlanta criteria. Three of these five cases $(3 / 5 ; 60 \%)$ were related to heavy alcohol use, and one other case $(1 / 5 ; 20 \%)$ was associated with biliary sludge. All cases of pancreatitis were considered mild and achieved resolution after medication discontinuation. From the same pooled analysis, the rate of major cardiac-related adverse events in eluxadolinetreated group $(3 / 1839 ; 0.2 \%)$ was not higher than that of placebo $(3 / 975 ; 0.3 \%) .{ }^{37}$ The cardiac adverse events in the eluxadoline-treated group all occurred in patients $\geq 70$ years old with known risk factors or a history of cardiovascular or pulmonary diseases. A single case of colon ischemia was reported in a 72-year-old female who developed nausea, vomiting, abdominal pain, rectal bleeding and hypotension 19 days after receiving eluxadoline. Colonoscopy and histology revealed colonic ischemia in ascending, transverse, descending and sigmoid colon. There was no evidence of constipation prior to presentation. This episode was selflimited and the patient recovered uneventfully.

In March 2017, the FDA released a warning regarding the increased risk of serious pancreatitis in eluxadoline-treated patients without a gallbladder. Based on data from FDA Adverse Event Reporting System (FAERS), 120 cases of serious pancreatitis or death were reported from May 2015 through February 2017. ${ }^{38}$ Seventy-six of these patients required hospitalization, among whom two patients died. Of the 68 cases with reported gallbladder status, 56 did not have a gallbladder (21/56 reported no history of alcohol abuse; 35/56 did not report alcohol use status). Both instances of death occurred in patients without a gallbladder. Of the 84 cases that reported adverse event onset timing, 48 occurred shortly after first or second doses of study drug, while 36 occurred after more prolonged use. A postmarketing surveillance study revealed that the risk of pancreatitis associated with eluxadoline use appeared to be higher than that of other agents (loperamide, diphenoxylate, oxycodone, and rifaximin) used to treat IBS-D. ${ }^{39}$

While data from FAERS provide essential information that permits assessment of risk and benefit associated with a drug of interest, it must be interpreted with caution due to several limitations. First, the heterogeneous source of reports from manufacturers, health professionals, and consumers (patients, family members, and lawyers) may result in the submission of biased information based on the level of medical knowledge and personal viewpoints. Second, there is no definitive evidence of causal relationship of any reported adverse events and the study drug given the lack of formal investigations of the reported cases. Finally, since reporting to FAERS is voluntary and not all adverse 
events were filed, true incidence of serious adverse events cannot be derived from these data. ${ }^{40}$ Nevertheless, these postmarking cases suggest that serious pancreatitis may occur in both patients with and without a gallbladder, and those without a gallbladder are at particularly increased risk despite screening for alcoholism and taking the recommended lower dose of eluxadoline at $75 \mathrm{mg}{ }^{41}$ Based on these reported data, FDA added a contraindication for eluxadoline use in patients without a gallbladder.

The mechanism of eluxadoline-induced SOS and pancreatitis is poorly understood. It is believed that the development of pancreatitis is secondary to SOS, but it remains puzzling why it occurs so quickly after the first doses. $\mu$ and $\delta$ - receptors are the two opioid receptors found on sphincter of Oddi. Activation of $\mu$ receptors leads to sphincter contraction, while stimulation of the $\delta$ receptors promotes sphincter relaxation. ${ }^{40}$ As a $\mu$-agonist and $\delta$-antagonist, eluxadoline induces contraction of sphincter of Oddi and prevents its relaxation. One possible explanation for the higher incidence of SOS in patients without a gallbladder is the loss of cholecystokinin-induced inhibition of sphincter of Oddi phasic contractions after cholecystectomy. ${ }^{42}$ Another hypothesis proposes that the gallbladder functions as a pressure reservoir to alleviate the increased biliary pressures induced by SOS, and thus such a protective mechanism is missing in patients without a gallbladder. ${ }^{43}$

Another important aspect of safety consideration of eluxadoline use relates to its abuse potential. The activity of eluxadoline on opioid receptors is thought to be peripherally restricted; there is minimal systemic absorption of eluxadoline administered orally, and this drug has a linear pharmacokinetics profile without significant accumulation on the twice-daily dosing regimen. ${ }^{44}$ Data related to misuse and abuse potential of eluxadoline have been assessed in clinical trials, with pooled safety data from IBS-2001, IBS-3001 and IBS-3002 showing no significant difference between the incidence of adverse events potentially related to abuse in eluxadoline-treated or placebo-treated patients. ${ }^{45}$ Subjective Opiate Withdrawal Scale score also did not differ significantly between the treatment and placebo arms. In two separate crossover studies, oral and intranasal abuse potential of eluxadoline, as compared to that of positive control oxycodone or placebo, was assessed in healthy recreational opioid users. ${ }^{46}$ When orally dosed, Drug Liking Visual Analog Scale (VAS) peak effect $\left(E_{\max }\right)$ score, measured on a bipolar scale $(0$ : strongly disliking; 50: neutral; 100: strongly liking), was significantly higher with larger doses of eluxadoline (300 and $1000 \mathrm{mg}$ ) in comparison to placebo. The scores of eluxadoline groups were significantly lower than those of oxycodone groups. When received through the intranasal route, Drug Liking VAS $\mathrm{E}_{\max }$ scores of eluxadoline groups did not differ significantly from that of placebo and were significantly lower than those of oxycodone groups. Overall data from these studies suggested the risk of abuse, dependence, or withdrawal associated with eluxadoline use is expected to be low.

\section{Identification and Selection of Patients for Eluxadoline}

Given that IBS encompasses a heterogenous group of disorders with varying mechanisms and presentations, understanding characteristics such as demographics, disease severity, and symptom pattern may guide management choices. A recent study assessed the impact of patient and disease characteristics on efficacy and safety of eluxadoline for IBS-D. ${ }^{47}$ Subgroups analyzed in this study include age ( $<65$ or $\geq 65$ years), sex (female or male), race (black, white, or other), BMI ( $<30 \mathrm{~kg} / \mathrm{m}^{2}$ or $\left.\geq 30 \mathrm{~kg} / \mathrm{m}^{2}\right)$, history of depression (presence or absence of depression), history of GERD symptoms (presence or absence of GERD symptoms), history of IBS symptoms (persistent versus wax/wane), and baseline pain $(<5,5-<8$, or $\geq 8)$. A greater proportion of patients demonstrated composite response in the eluxadoline group than placebo in all age, sex, race, comorbidity, and disease characteristic subgroups. In patients older than 65 years of age, a larger proportion of patients receiving a lower dose of eluxadoline $(75 \mathrm{mg}$ ) achieved composite, abdominal pain, and stool consistency responses than those receiving the higher dose $(100 \mathrm{mg})$. The percentage of patients experiencing at least one adverse event is slightly higher in the $\geq 65$ years $(66 \%)$ and female sex subgroups $(62 \%)$ in comparison to their counterparts ( $59 \%$ for age $<65 \% ; 53 \%$ for males).

Current FDA contraindications for eluxadoline use in patients with IBS-D include absence of a gallbladder, biliary duct obstruction or sphincter of Oddi dysfunction, alcoholism ( $>3$ drinks per day), history of pancreatitis or structural diseases of the pancreas, known hypersensitivity reaction to eluxadoline, severe hepatic impairment (ChildPugh Class C), or severe constipation. ${ }^{27}$ For those with mild or moderate hepatic impairment, the recommended dosage is $75 \mathrm{mg}$ instead of $100 \mathrm{mg}$ BID. Given the potential serious (while uncommon) adverse events of SOS, pancreatitis, and death associated with eluxadoline, the use of eluxadoline does merit caution. Adherence to 
appropriate patient selection and dosing recommendation, as well as close monitoring after medication initiation, is of particular importance. Our own practice is to avoid using this agent as first-line therapy for IBS-D. Since alosetron is only approved for use in women with severe IBS-D, eluxadoline provides an additional option for male IBS-D patients. Due to adverse events observed in chronic heavy alcohol users, we are more hesitant using eluxadoline in patients that have a tendency to consume a significant amount of alcohol at once (binge-drinkers), especially in college-aged patients - a common IBS demographic seen in our clinic. That said, there are currently no data assessing adverse events associated with eluxadoline in patients with binge-drinking habits as opposed to chronic, heavy alcohol use.

\section{Conclusion}

Developing effective treatments for IBS-D has been challenging, likely because IBS-D is a heterogenous disorder with a varied clinical presentation and underlying mechanisms that remain poorly understood. Phase III clinical trials showed that more than $25 \%$ of eluxadoline-treated patients achieved composite clinical response, defined by a reduction of abdominal pain and improvement in stool consistency. Trial data that directly compare the efficacy of eluxadoline with other FDA-approved medications such as alosetron or rifaximin are currently lacking, which is important for determining the place of eluxadoline amongst the hierarchy of IBS-D treatments. The effect of co-administration with other agents should also be explored. Additional unanswered questions include whether eluxadoline can be discontinued after a certain period of time with a durable response and whether eluxadoline can be effective and safe as an on-demand agent. Finally, further studies examining the differences between eluxadoline responders versus non-responders will provide insights that would guide selection of patients that are most likely to benefit from eluxadoline.

\section{Disclosure}

KS reports research supports and/or personal fees from Gelesis, AstraZeneca, Takeda, and Urovant; he is a consultant/speaker for Shire, Synergy, Bayer. He has a Data and Safety Monitoring Board (DSMB) membership with Arena. The authors report no other conflicts of interest in this work.

\section{References}

1. Ford AC, Lacy BE, Talley NJ. Irritable bowel syndrome. $N$ Engl $J$ Med. 2017;376(26):2566-2578. doi:10.1056/NEJMra1607547

2. Lovell RM, Ford AC. Global prevalence of and risk factors for irritable bowel syndrome: a meta-analysis. Clin Gastroenterol Hepatol. 2012;10(7):712-721 e714. doi:10.1016/j.cgh.2012.02.029

3. Gralnek IM, Hays RD, Kilbourne A, Naliboff B, Mayer EA. The impact of irritable bowel syndrome on health-related quality of life. Gastroenterology. 2000;119(3):654-660. doi:10.1053/ gast.2000.16484

4. Frandemark A, Tornblom H, Jakobsson S, Work Productivity SM. Activity Impairment in Irritable Bowel Syndrome (IBS): a multifaceted problem. Am J Gastroenterol. 2018;113(10):1540-1549. doi:10.1038/ s41395-018-0262-x

5. Ng QX, Soh AYS, Loke W, Lim DY, Yeo WS. The role of inflammation in irritable bowel syndrome (IBS). $J$ Inflamm Res. 2018;11:345-349. doi:10.2147/JIR.S174982

6. Holtmann GJ, Ford AC, Talley NJ. Pathophysiology of irritable bowel syndrome. Lancet Gastroenterol Hepatol. 2016;1(2):133-146. doi:10.1016/S2468-1253(16)30023-1

7. Drossman DA. Functional gastrointestinal disorders: history, pathophysiology, clinical features and Rome IV. Gastroenterology. 2016;150:1262-1279.e2. doi:10.1053/j.gastro.2016.02.032

8. Lacy BE, Mearin F, Chang L, et al. Bowel disorders. Gastroenterology. 2016;150(6):1393. doi:10.1053/j.gastro.2016.02.031

9. Lucak S, Chang L, Halpert A, Harris LA. Current and emergent pharmacologic treatments for irritable bowel syndrome with diarrhea: evidence-based treatment in practice. Therap Adv Gastroenterol. 2017;10(2):253-275. doi:10.1177/1756283X16663396

10. Hovdenak N. Loperamide treatment of the irritable bowel syndrome. Scand J Gastroenterol Suppl. 1987;130:81-84. doi:10.3109/003655287 09091004

11. Lavo B, Stenstam M, Nielsen A-L. Loperamide in treatment of irritable bowel syndrome-a double-blind placebo controlled study. Scand J Gastroenterol Suppl. 1987;22:77-80. doi:10.3109/00365528709091003

12. Ford AC, Moayyedi P, Chey WD, et al. American College of Gastroenterology Monograph on Management of Irritable Bowel Syndrome. Am J Gastroenterol. 2018;113(Suppl 2):1-18. doi:10.1038/ s41395-018-0084-x

13. Wagstaff AJ, Ormrod D, Spencer CM. Tianeptine: a review of its use in depressive disorders. CNS Drugs. 2001;15(3):231-259. doi:10.2165/ 00023210-200115030-00006

14. Sohn W, Lee OY, Kwon JG, et al. Tianeptine vs amitriptyline for the treatment of irritable bowel syndrome with diarrhea: a multicenter, openlabel, non-inferiority, randomized controlled study. Neurogastroenterol Motil. 2012;24(9):860-e398. doi:10.1111/j.1365-2982.2012.01945.x

15. Ng QX, Soh AYS, Lim DY, Yeo WS. Agomelatine, a novel therapeutic option for the management of irritable bowel syndrome. J Clin Pharm Ther. 2018;43(5):752-756. doi:10.1111/ jcpt.12749

16. Balakina IV, Mironova T, Golovanova EN. [Efficacy and safety of valdoxan in patients with irritable bowel syndrome]. Zh Nevrol Psikhiatr Im S S Korsakova. 2014;114(4):90-92.

17. Lewis JH. Alosetron for severe diarrhea-predominant irritable bowel syndrome: safety and efficacy in perspective. Expert Rev Gastroenterol Hepatol. 2010;4(1):13-29. doi:10.1586/egh.09.72

18. Tong K, Nicandro JP, Shringarpure R, Chuang E, Chang L. A 9-year evaluation of temporal trends in alosetron postmarketing safety under the risk management program. Therap Adv Gastroenterol. 2013;6 (5):344-357. doi:10.1177/1756283X13491798

19. US Food and Drug Administration. Highlights of prescribing information for lotronex (alosetron). FDA Label; 2008. Available from: https://www.accessdata.fda.gov/drugsatfda_docs/label/2008/ 021107s013lbl.pdf. Accessed December 3, 2019. 
20. Chang L, Lembo A, Sultan S. American Gastroenterological Association Institute Technical Review on the pharmacological management of irritable bowel syndrome. Gastroenterology. 2014;147 (5):1149-1172 e1142. doi:10.1053/j.gastro.2014.09.002

21. Krause R, Ameen V, Gordon SH, et al. A randomized, double-blind, placebo-controlled study to assess efficacy and safety of $0.5 \mathrm{mg}$ and $1 \mathrm{mg}$ alosetron in women with severe diarrhea-predominant IBS. Am $J$ Gastroenterol. 2007;102(8):1709-1719. doi:10.1111/ajg.2007.102. issue- 8

22. Lembo T, Wright RA, Bagby B, et al. Alosetron controls bowel urgency and provides global symptom improvement in women with diarrhea-predominant irritable bowel syndrome. Am J Gastroenterol. 2001;96(9):2662-2670. doi:10.1111/j.1572-0241.2001.04128.x

23. US Food and Drug Administration. Highlights of Prescribing Information for Xifaxan (rifaximin). FDA Label; 2017. Available from: https://www.accessdata.fda.gov/drugsatfda_docs/label/2017/ 021361s023lbl.pdf. Accessed December 3, 2019.

24. Pimentel M, Lembo A, Chey WD, et al. Rifaximin therapy for patients with irritable bowel syndrome without constipation. New Engl J Med. 2011;364(1):22-32. doi:10.1056/NEJMoa1004409

25. Lembo A, Pimentel M, Rao SS, et al. Repeat treatment with rifaximin is safe and effective in patients with diarrhea-predominant irritable bowel syndrome. Gastroenterology. 2016;151(6):1113-1121. doi:10.1053/j. gastro.2016.08.003

26. Barshop K, Staller K. Eluxadoline in irritable bowel syndrome with diarrhea: rationale, evidence and place in therapy. Ther Adv Chronic Dis. 2017;8(11):153-160. doi:10.1177/2040622317714389

27. US Food and Drug Administration. Highlights of prescribing information for viberzi (eluxadoline). FDA Label; 2018. Available from: https://www.accessdata.fda.gov/drugsatfda_docs/label/2018/ 206940s006lbl.pdf. Accessed December 32019.

28. Holzer P. Opioid receptors in the gastrointestinal tract. Regul Pept. 2009;155(1-3):11-17. doi:10.1016/j.regpep.2009.03.012

29. Wade PR, Palmer JM, McKenney S, et al. Modulation of gastrointestinal function by MuDelta, a mixed mu opioid receptor agonist/mu opioid receptor antagonist. Brit $J$ Pharmacol. 2012;167(5):1111-1125. doi:10.1111/j.1476-5381.2012.02068.x

30. Dove LS, Lembo A, Randall CW, et al. Eluxadoline benefits patients with irritable bowel syndrome with diarrhea in a phase 2 study. Gastroenterology. 2013;145(2):329-338 e321. doi:10.1053/j.gastro.2013. 04.006

31. U.S. Food and. Drug Administration Center for Drug Evaluation and Research (CDER). In: Guidance for Industry, Irritable Bowel Syndrome - Clinical Evaluation of Drugs for Treatment; May 2012.

32. Lembo AJ, Lacy BE, Zuckerman MJ, et al. Eluxadoline for irritable bowel syndrome with diarrhea. $N$ Engl J Med. 2016;374(3):242-253. doi:10.1056/NEJMoa1505180

33. Chey WD, Dove LS, Andrae DA, Covington PS. Early response predicts a sustained response to eluxadoline in patients with irritable bowel syndrome with diarrhoea in two Phase 3 studies. Aliment Pharmacol Ther. 2017;45(10):1319-1328. doi:10.1111/apt.14031

34. Lacy BE, Chey WD, Cash BD, Lembo AJ, Dove LS, Covington PS. Eluxadoline efficacy in IBS-D patients who report prior loperamide use. Am J Gastroenterol. 2017;112(6):924-932. doi:10.1038/ajg.2017.72

Drug Design, Development and Therapy

\section{Publish your work in this journal}

Drug Design, Development and Therapy is an international, peerreviewed open-access journal that spans the spectrum of drug design and development through to clinical applications. Clinical outcomes, patient safety, and programs for the development and effective, safe, and sustained use of medicines are a feature of the journal, which has also
35. Brenner DM, Sayuk GS, Gutman CR, et al. Efficacy and safety of eluxadoline in patients with irritable bowel syndrome with diarrhea who report inadequate symptom control with loperamide: RELIEF Phase 4 study. Am J Gastroenterol. 2019;114:1502-1511. doi:10.14309/ajg. 0000000000000327

36. Black CJ, Burr NE, Camilleri M, et al. Efficacy of pharmacological therapies in patients with IBS with diarrhoea or mixed stool pattern: systematic review and network meta-analysis. Gut. 2019;69:74-82.

37. Cash BD, Lacy BE, Schoenfeld PS, Dove LS, Covington PS. Safety of eluxadoline in patients with irritable bowel syndrome with diarrhea. Am J Gastroenterol. 2017;112(2):365-374. doi:10.1038/ ajg. 2016.542

38. US Food and Drug Administration. FDA Drug Safety Communication: FDA Warns About Increased Risk of Serious Pancreatitis with Irritable Bowel Drug Viberzi (Eluxadoline) in Patients Without a Gallbladder. Center for Drug Evaluation and Research; 2017. Available from: https:// www.fda.gov/Drugs/DrugSafety/ucm546154.htm. Accessed December $3,2019$.

39. Gawron AJ, Bielefeldt K. Risk of pancreatitis following treatment of irritable bowel syndrome with eluxadoline. Clin Gastroenterol Hepatol. 2018;16(3):378-384 e372. doi:10.1016/j.cgh.2017.08.006

40. Chedid V, Vijayvargiya P, Camilleri M. Advantages and limitations of the federal adverse events reporting system in assessing adverse event reporting for eluxadoline. Clin Gastroenterol Hepatol. 2018;16 (3):336-338. doi:10.1016/j.cgh.2017.11.025

41. Harinstein L, Wu E, Brinker A. Postmarketing cases of eluxadolineassociated pancreatitis in patients with or without a gallbladder. Aliment Pharmacol Ther. 2018;47(6):809-815. doi:10.1111/apt.14504

42. Afghani E, Lo SK, Covington PS, Cash BD, Pandol SJ. Sphincter of Oddi function and risk factors for dysfunction. Front Nutr. 2017;4:1. doi:10.3389/fnut.2017.00001

43. Croteau R, Barkin JS. Safety of Eluxadoline in patients with irritable bowel syndrome. Am J Gastroenterol. 2017;112(10):1616. doi:10.1038/ ajg.2017.249

44. Davenport JM, Covington P, Bonifacio L, McIntyre G, Venitz J. Effect of uptake transporters OAT3 and OATP1B1 and efflux transporter MRP2 on the pharmacokinetics of eluxadoline. J Clin Pharmacol. 2015;55(5):534-542. doi:10.1002/jcph.442

45. Fant RV, Henningfield JE, Cash BD, Dove LS, Covington PS. Eluxadoline demonstrates a lack of abuse potential in Phase 2 and 3 studies of patients with irritable bowel syndrome with diarrhea. Clin Gastroenterol Hepatol. 2017;15(7):1021-1029 e1026. doi:10.1016/j. cgh.2017.01.026

46. Levy-Cooperman N, McIntyre G, Bonifacio L, et al. Abuse potential and pharmacodynamic characteristics of oral and intranasal eluxadoline, a mixed mu- and kappa-opioid receptor agonist and delta-opioid receptor antagonist. J Pharmacol Exp Ther. 2016;359(3):471-481. doi:10.1124/jpet.116.236547

47. Lacy BE, Harris LA, Chang L, et al. Impact of patient and disease characteristics on the efficacy and safety of eluxadoline for IBS-D: a subgroup analysis of phase III trials. Therap Adv Gastroenterol. 2019;12:1756284819841290. doi:10.1177/1756284819841290 been accepted for indexing on PubMed Central. The manuscript management system is completely online and includes a very quick and fair peer-review system, which is all easy to use. Visit http://www. dovepress.com/testimonials.php to read real quotes from published authors.

\section{Dovepress}

